\title{
Impacted Maxillary Central Incisors Associated with Bilateral Mesiodentes: A Case Report
}

\author{
Mine Gecgelen Cesur ${ }^{1}$, Elcin Esenlik ${ }^{2^{*}}$ and Yavuz Findik ${ }^{3}$ \\ ${ }^{1}$ Adnan Menderes University, Faculty of Dentistry, Department of Orthodontics, Aydin, Turkey \\ ${ }^{2}$ Associate Professor, Suleyman Demirel University, Faculty of Dentistry, Department of Orthodontics, Isparta, Turkey \\ ${ }^{3}$ Assistant Professor, Suleyman Demirel University, Faculty of Dentistry, Department of Oral and Maxillofacial Surgery, Isparta, Turkey
}

*Corresponding author: Elcin Esenlik , Faculty of Dentistry , Department of Orthodontics, The Peace Envoy, Süleyman Demirel University, Istanbul, TURKEY, Tel:+90 2462118807; E-mail: elcinesenlik@gmail.com

Received date: May 22, 2014, Accepted date: June 27, 2014, Published date: July 4, 2014

Copyright: (c) 2014 Esenlik E, et al. This is an open-access article distributed under the terms of the Creative Commons Attribution License, which permits unrestricted use, distribution, and reproduction in any medium, provided the original author and source are credited

\begin{abstract}
The purpose of this paper was to present the surgical exposure and orthodontic treatment of an 11-year-old boy with horizontally impacted permanent maxillary central incisors associated with bilateral mesiodentes. Panaromic and upper anterior occlusal radiographs showed horizontally impacted maxillary central incisors, vertically impacted molariform mesiodens, and rotated mesiodens located at the site of the maxillary right central incisor. The treatment plan included extraction of the erupted mesiodens, surgical extraction of the impacted mesiodens, surgical exposure of the permanent central incisors, and orthodontic traction and alignment to achieve a normal occlusion. After 14 months of treatment, the central incisors erupted into the oral cavity. The impacted maxillary central incisors were successfully positioned to their proper alignment via surgical crown exposure and orthodontic traction. Ideal overjet, overbite, and Class I molar and canine relationships were also achieved. At the completion of treatment, the exposed incisors exhibited an acceptable gingival contour and attached gingiva. After 2 years of follow-up, a stable occlusion was maintained with only minor relapse at the right central incisor.
\end{abstract}

Keywords: Impacted teeth; Mesiodens; Orthodontic traction; Supernumerary teeth; Surgical exposure

\section{Introduction}

Tooth impaction refers to the failure of teeth to erupt into the mouth within the normal time, where the failure of eruption appears to originate from mechanical blocking. Tooth impaction may result from a number of local causal factors. These include arch length discrepancy, ectopic positioning of the teeth, presence of supernumerary teeth, mucosal or bony barriers, and retained deciduous teeth $[1,2]$. The prevalence of supernumerary teeth was found to be 2.7 in a sample of Turkish children, and the most commonly encountered supernumeraries were mesiodens (51.0\%) [3]. A mesiodens is a supernumerary tooth located in the maxillary central incisor region [4]. The incidence rate of mesiodens is up to $1.9 \%$ in deciduous teeth and between $0.15 \%$ and $3.8 \%$ in permanent teeth [5]. A sex-linked pattern for the occurrence of mesiodens has been proposed, as male patients are affected twice as frequently as female patients $[3,6]$. Unilateral or bilateral teeth impaction may be frequently observed at a solitary location between the 2 central incisors. Bilateral mesiodens occur in $13 \%$ of all cases [4]. The presence of mesiodens generally results in clinical and aesthetic problems, including failure to erupt, displacement of a permanent tooth, and dentigerous cyst formation and bilateral mesiodens has been found to result in significantly more problems than unilateral mesiodens, in previous studies.

Surgical extraction is one treatment option for incisors showing severe horizontal impaction. Alternative treatment methods for central incisors showing severe horizontal impaction have been reported in the literature. Treatment methods can evidently vary depending on the anatomic location involved and the wider aspects of the patient's dentition. In previous reports, different treatment modalities such as a combination of surgical crown exposure and removable plates, active palatal arches, or fixed orthodontic appliances have been applied for aligning the teeth into their proper positions [7-9]. The purpose of this report is to present the case of an 11-year-old boy with horizontally impacted permanent maxillary central incisors associated with bilateral mesiodens who underwent surgical exposure followed by orthodontic treatment.

\section{Case Report}

An 11-year-old boy was referred to the Department of Orthodontics with the chief complaint of an unerupted maxillary central incisor. The child was otherwise physically healthy and had no history of medical or dental trauma. The patient had a skeletal Class I malocclusion and a balanced facial pattern. Intraoral examination revealed that he had permanent dentition and Angle's Class I molar and Class II canine relationships. Clinical examination revealed missing maxillary permanent central incisors and the presence of a rotated mesiodens in place of the maxillary right central incisor. This supplemental tooth was very similar to the natural teeth in both size and shape. Arch length discrepancy was $3.0 \mathrm{~mm}$ for the maxilla and $1.5 \mathrm{~mm}$ for the mandible (Figure 1).

A panaromic radiograph showed horizontally impacted maxillary central incisors and vertically impacted molariform mesiodens with a premolar-like crown and an incompletely formed root (Figure 2). To determine the localization of the mesiodens and impacted teeth, upper occlusal radiography was performed, which showed the presence of teeth on the palatal side (Figure 3). 


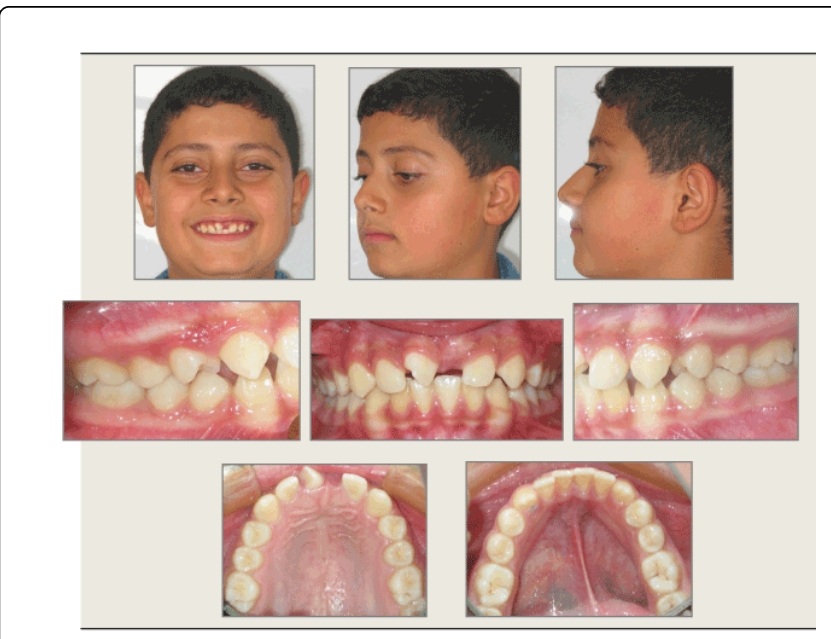

Figure 1: Intraoral and extraoral photographs of the patient before treatment.

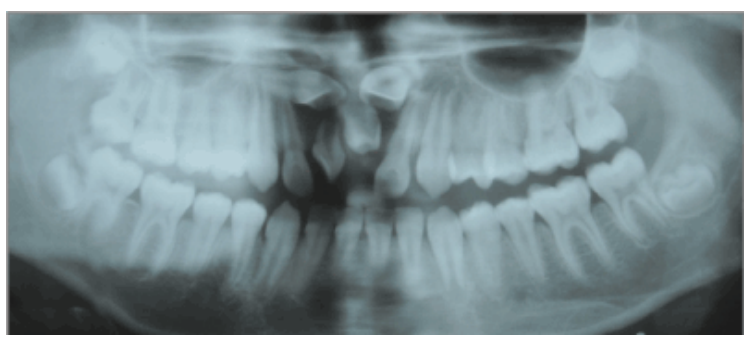

Figure 2: Panoramic radiograph showing impacted central incisors and mesiodentes.

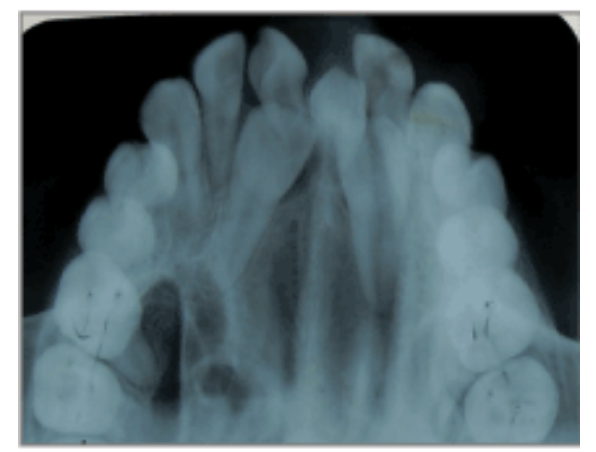

Figure 3: Maxillary occlusal radiograph showing impacted teeth.

On the basis of clinical and radiographic findings, the treatment plan included the following steps:

Extraction of the erupted mesiodens

Surgical extraction of the impacted mesiodens

Surgical exposure of the permanent central incisors

Orthodontic traction and alignment to obtain a normal occlusion
Pre adjusted fixed orthodontic appliances $(0.018 ")$ were bonded to the upper and lower arches. Initially, $0.016 "$ and 0.018 " nickel titanium arch wires, and $0.016 " \times 0.022^{\prime \prime}$ rectangular arch wires were placed on the upper and lower arches, respectively (Figure 4). An open-coil spring was inserted between the 2 upper lateral teeth in an effort to obtain adequate space for the central teeth. After leveling and aligning, surgical intervention was performed under local anesthesia. The erupted mesiodens was extracted and the impacted mesiodens was removed surgically. Surgical exposure of the right and left central incisors was achieved with the closed-eruption surgical flap technique.

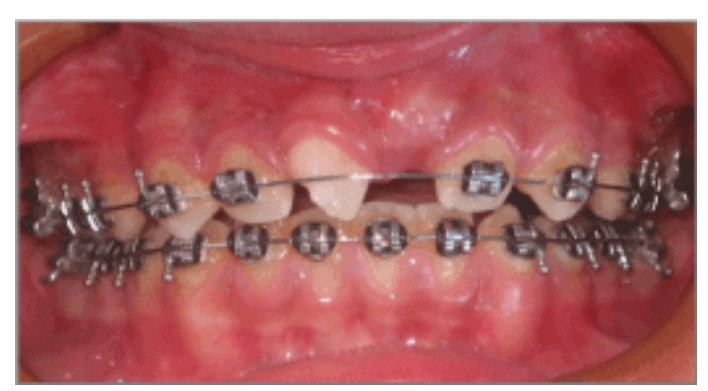

Figure 4: Intraoral photograph showing the alignment with rectangular $\mathrm{Ni}-\mathrm{Ti}$ arch wire.

After surgical exposure, lingual buttons were bonded to the impacted incisors. The flap was repositioned and sutured for a week. A 0.010 " inch ligature wire was fixed over each button and passed through the mucosa. Traction was applied through the archwire by tying these ligature wires to the maxillary central incisors. The traction was continued until the maxillary central incisors reached the occlusal plane. Once each central incisor was considerably visible, the lingual button was replaced with brackets. After 14 months of treatment, the central incisors were orthodontically aligned into their proper positions. Periodic radiographs were taken to monitor the movement of the impacted incisors (Figure 5). The patient was instructed to wear Class II and interdigitation elastics. Active orthodontic treatment time was 31 months. Debonding was done after achieving good intercuspation and normal overjet and overbite. Retention was provided by an essix retainer.

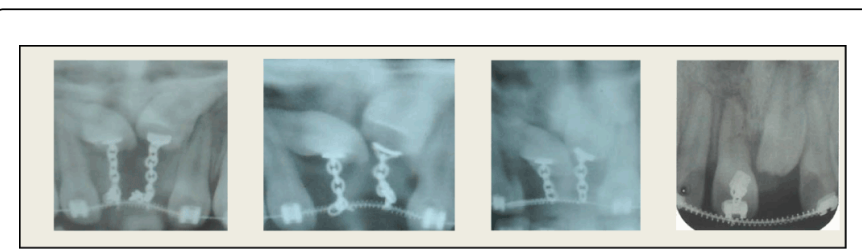

Figure 5: Periodic radiographs of patient for monitoring the movement of the impacted incisors.

Lastly, the impacted maxillary central incisors were successfully positioned into their proper alignments via surgical crown exposure and orthodontic traction. Ideal overjet, overbite, and Class I molar and canine relationships were also achieved. After completion of the treatment, the exposed incisors exhibited an acceptable gingival contour and attached gingiva (Figures 6 and 7). 


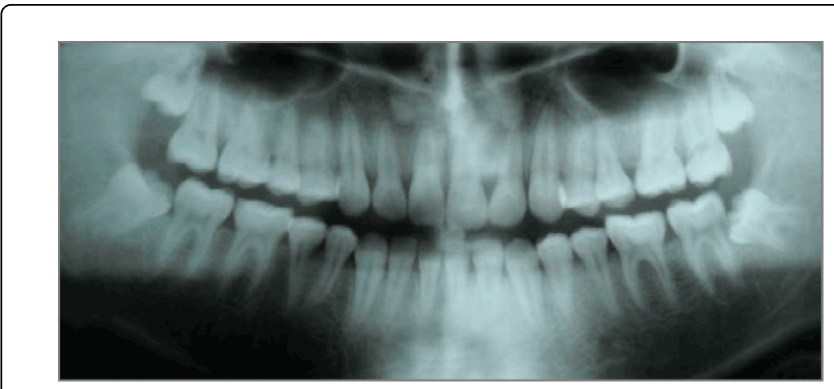

Figure 6: Post-treatment panoramic radiograph.

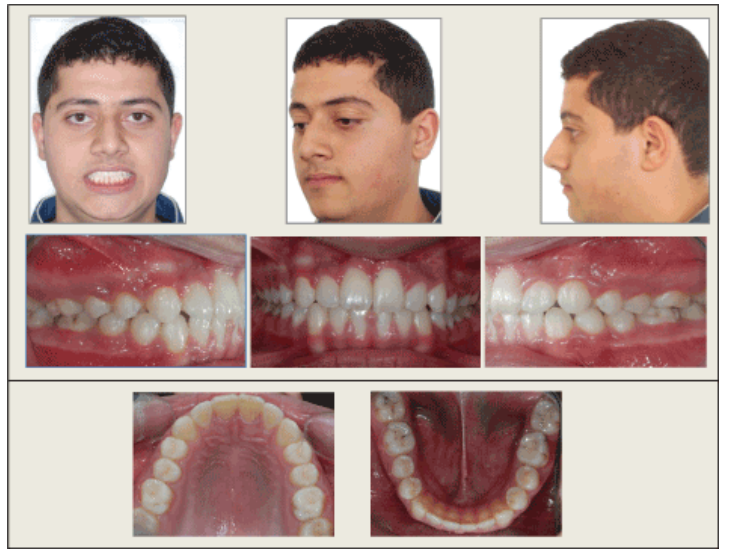

Figure 7: Intraoral and extraoral photographs of the patient after treatment.

Analysis of the treatment outcome 2 years after treatment showed an optimal facial pattern with a balanced facial and soft tissue profile. A stable occlusion was maintained, with only minor relapse at the right central incisor. Overbite and overjet were normal. The gingival levels of the incisors were aesthetically pleasant and had good periodontal support (Figure 8). It was not necessary to perform periodontal surgery for gingival leveling. The periodontium and root structure showed good integrity (Figure 9).

\section{Discussion}

Impaction defines the phenomenon in which a tooth cannot or does not erupt into its normal functional position. Tooth impaction can originate from numerous localized etiological factors, including ectopic tooth development or eruption, thick mucosal or bony barriers, premature apical closure, unfavorable tooth rotation, altered eruption sequence, premature loss of a deciduous tooth, retained or ankylosed deciduous teeth, presence of supernumerary teeth or a cyst, insufficient space in the dental arch, or as a sequelae of oral trauma [2]. Most of the mesiodens account for impacted central teeth. In this case report, bilateral mesiodens were thought to be the main etiologic factor contributing to the retention of the maxillary central incisors.

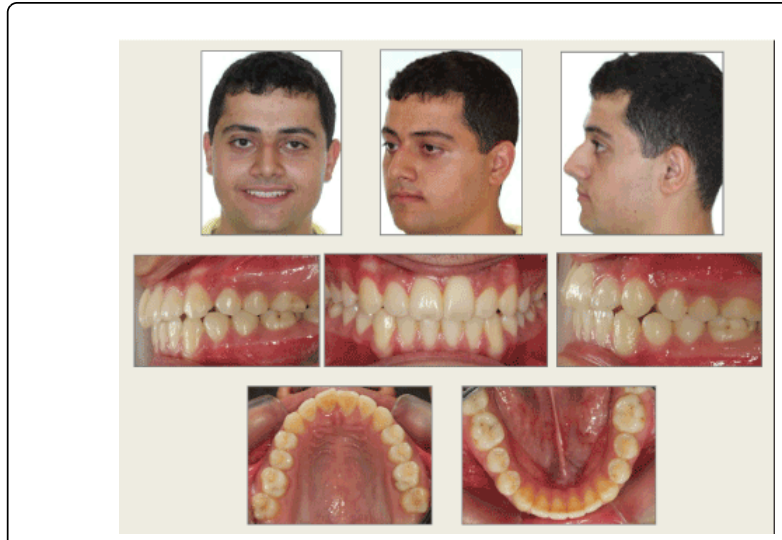

Figure 8: Intraoral and extraoral photographs of the patient at 2 year post-retention.

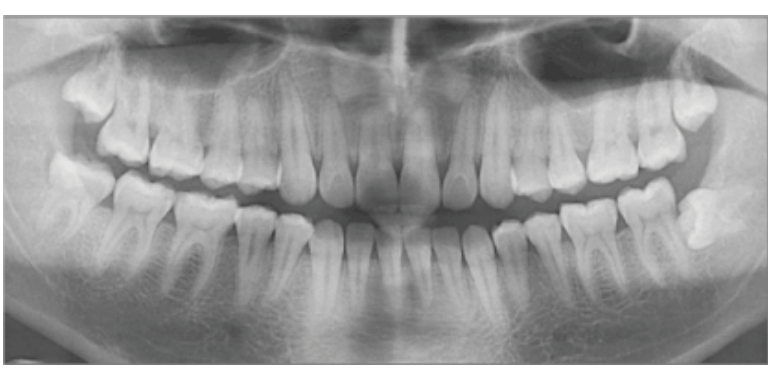

Figure 9: Panoramic radiograph at 2 year post-retention

Mesiodens in the permanent dentition present in a wide variety of forms. Primosch classified them as supplemental or rudimentary on the basis of shape. Supplemental or eumorphic are the terms used to refer to supernumerary teeth of normal size and shape, which may also be termed incisiform. Rudimentary or dysmorphic are the terms used to describe teeth of abnormal shape and smaller size, including conical, tuberculate, and molariform teeth $[6,10]$. In the present case, one of the mesiodens erupted in the location of the maxillary right central incisor, and exhibited a supplemental shape; it resembled the natural teeth in both size and shape. The other mesiodens was vertically impacted and was of the rudimentary type, with a premolarlike crown and an incompletely formed root.

Central incisors are of great importance with regard to both esthetics and function. Unerupted maxillary incisors can hinder the appropriate growth of alveolar bone, particularly in young patients as they tend to be undergoing active alveolar bone development. Therefore, most clinicians attempt placement of the incisors by different treatment approaches. In addition to considerations relating to eruption of the central teeth, the importance of avoiding any bone destruction has been emphasized in the management of this problem. Surgical exposure followed by orthodontic traction, surgical repositioning followed by orthodontic alignment, and surgical re implantation followed by orthodontic traction, or re implantation alone, were the most commonly utilized treatment modalities for a horizontal or inverted displaced maxillary permanent central incisor [11]. Re implantation is an alternative method to extraction that has been used for treating impacted teeth in ectopic positions [12]. While 
successful re implantations in this context have been reported in the literature by some authors, others have reported that the survival rates of such re implantations are limited to 8-10 years. Surgical repositioning or reimplantation followed by orthodontic traction are alternative treatment choices [13]. These techniques are generally suggested for inverted impacted central incisors since any attachment is unable to attach to the impacted tooth's surface. Surgical exposure followed by orthodontic traction is the most common treatment for horizontally impacted maxillary central incisors [14-17]. In the present case report, surgical exposure and orthodontic traction were preferred as the treatment modalities, as the position of the central incisors was not inverted. The aim of adopting this approach was to take advantage of the active alveolar growth and incomplete root development typical of younger patients.

Fixed orthodontic treatment is one of the treatments of choice for the management of impacted permanent incisors. Factors to be considered while planning fixed orthodontic treatment include gaining adequate space, placement of attachments, and the choice between open or closed eruption techniques [18]. For erupting central teeth, there may not be enough space on the arch for the unerupted teeth, as this space is generally occupied by adjacent or supernumerary teeth. It has been suggested that orthodontic traction should not be initiated unless adequate space on the arch is achieved, in order to avoid any root contacts with adjacent teeth and to prevent future periodontal problems. Most authors report initiating orthodontic traction from the lingual surface by applying lingual buttons, Begg brackets, or edgewise incisor brackets [19]. Lin has suggested that placement of the attachment on the labial surface at an acute angle to the dilacerated tooth could cause more bone reduction, thus supporting its placement on the lingual surface [15]. To bring the impacted tooth to its natural position in the present case, lingual buttons were initially bonded to the palatal surface of the impacted tooth while a mucogingival flap was opened. Neither operative nor orthodontic complications were observed at this stage. The buttons were then subsequently replaced with conventional straight wire brackets. In a case reported by Chawla and Kapur [19], however, a Begg bracket bonded to the labial surface of the impacted tooth was very effective in bringing the tooth to its natural position. The authors also stated that no destruction of bone was evident; rather, the tooth maintained favorable bone support throughout treatment. Similarly, in a case report by Kalaskar and Kalaskar [18], a bracket was bonded to the labial surface of impacted permanent maxillary right central incisors. They stated that no excessive bone reduction was observed in their case. In our opinion, the selection of a surface should be made on a case-by-case basis. If the attachment is likely to cause trauma to the labial mucosa, lingual placement may be more favorable. It has been reported that surgical exposure followed by orthodontic traction of horizontally impacted maxillary central incisors can result in unaesthetic gingival tissue of the exposed incisor, requiring periodontal surgery [11].

Becker et al. [20] has suggested that a closed-eruption technique is capable of achieving a superior outcome in terms of aesthetics and periodontal health. In the present case, the closed-eruption technique was used and no periodontal treatment was necessary. The position, periodontal attachment, gingival contour, and probing depths of the incisors were normal. In a case report by Chawla and Kapur [19], this technique was not possible as the tooth was already protruding through the mucosa. However, they reported that aesthetic results were achieved at the end of the treatment. Similarly, Thosar and Vibhute [1], Kalaskar and Kalaskar [18] did not use the closed- eruption surgical technique in their cases. In our case, after 2 years of follow-up, a stable occlusion was maintained with only minor relapse at the right central incisor. The possible cause of this relapse was attributed the patient not using the essix retainer.

\section{Conclusion}

Maxillary impacted central incisors were successfully positioned in the maxillary arch by surgical exposure and orthodontic traction. Treatment resulted in balanced and stable occlusion between the maxillary and mandibular arches, an adequate bone level and attached gingiva, and good stability for 2 years post-retention.

\section{References}

1. Thosar NR, Vibhute P (2006) Surgical and orthodontic treatment of an impacted permanent central incisor: a case report. J Indian Soc Pedod Prev Dent 24: 100-103.

2. Ozan F, Kara I, Ay S (2009) Impacted mandibular permanent incisors associated with a supernumerary tooth: a case report. Eur J Dent 3: 324-328.

3. Esenlik E, Sayin MO, Atilla AO, Ozen T, Altun C, et al. (2009) Supernumerary teeth in a Turkish population. Am J Orthod Dentofacial Orthop 136: 848-852.

4. Kazanci F, Celikoglu M, Miloglu O, Yildirim H, Ceylan I (2011) The frequency and characteristics of mesiodens in a Turkish patient population. Eur J Dent 5: 361-365.

5. Srivatsan P, Aravindha Babu N (2007) Mesiodens with an unusual morphology and multiple impacted supernumerary teeth in a nonsyndromic patient. Indian J Dent Res 18: 138-140.

6. Russell KA, Folwarczna MA (2003) Mesiodens--diagnosis and management of a common supernumerary tooth. J Can Dent Assoc 69: 362-366.

7. Kocadereli I, Turgut MD (2005) Surgical and orthodontic treatment of an impacted permanent incisor: case report. Dent Traumatol 21: 234-239.

8. Sabuncuoglu FA, Olmez H, Esenlik E (2011) Orthodontic approach to dilacerated central incisor localized horizontally on the anterior nasal spine: a case report. J Dent Child (Chic) 78: 168-172.

9. Pavlidis D, Daratsianos N, Jäger A (2011) Treatment of an impacted dilacerated maxillary central incisor. Am J Orthod Dentofacial Orthop 139: 378-387.

10. Primosch RE (1981) Anterior supernumerary teeth--assessment and surgical intervention in children. Pediatr Dent 3: 204-215.

11. Kuroe K, Tomonari H, Soejima K, Maeda A (2006) Surgical repositioning of a developing maxillary permanent central incisor in a horizontal position: spontaneous eruption and root formation. Eur J Orthod 28: 206-209.

12. Ulusoy AT, Akkocaoglu M, Akan S, Kocadereli I, Cehreli ZC (2009) Reimplantation of an inverted maxillary premolar: case report of a multidisciplinary treatment approach. J Clin Pediatr Dent 33: 279-282.

13. Agrait EM, Levy D, Gil M, Singh GD (2003) Repositioning an inverted maxillary central incisor using a combination of replantation and orthodontic movement: a clinical case report. Pediatr Dent 25: 157-160.

14. McNamara T, Woolfe SN, McNamara CM (1998) Orthodontic management of a dilacerated maxillary central incisor with an unusual sequela. J Clin Orthod 32: 293-297.

15. Lin YT (1999) Treatment of an impacted dilacerated maxillary central incisor. Am J Orthod Dentofacial Orthop 115: 406-409.

16. Tsai TP (2002) Surgical repositioning of an impacted dilacerated incisor in mixed dentition. J Am Dent Assoc 133: 61-66.

17. Uematsu S, Uematsu T, Furusawa K, Deguchi T, Kurihara S (2004) Orthodontic treatment of an impacted dilacerated maxillary central incisor combined with surgical exposure and apicoectomy. Angle Orthod 74: $132-136$ 
Citation: Mine Gecgelen Cesur, Elcin Esenlik, Yavuz Findik (2014) Impacted Maxillary Central Incisors Associated with Bilateral Mesiodentes: A Case Report. Biol Med 6: 204. doi:10.4172/0974-8369.1000204

Page 5 of 5

18. Kalaskar RR, Kalaskar AR (2011) Multidisciplinary management of impacted central incisors due to supernumerary teeth and an associated dentigerous cyst. Contemp Clin Dent 2: 53-58.

19. Chawla HS, Kapur A (2009) Orthodontic management of faciolingual horizontally impacted maxillary central incisor. J Indian Soc Pedod Prev Dent 27: 65-69.
20. Becker A, Brin I, Ben-Bassat Y, Zilberman Y, Chaushu S (2002) Closederuption surgical technique for impacted maxillary incisors: a postorthodontic periodontal evaluation. Am J Orthod Dentofacial Orthop 122: 9-14 